\title{
Elastomer Karakterizasyon Test Sistemlerinin Modellenmesi ve Parametrik Analizleri
}

\author{
Göktürk Taşağ $11^{1}$, Berk Başgöl ${ }^{2}$, Muzaffer Metin ${ }^{3 *}$, Timuçin Bayram ${ }^{4}$ \\ ${ }^{1}$ Yıldız Teknik Üniversitesi, Fen Bilimleri Enstitüsü, Makine Mühendisliği Anabilim Dalı, Makine Teorisi ve Kontrol Yüksek Lisans Programı İstanbul, Türkiye \\ (ORCID: 0000-0002-8816-6325) gokturk.tasagil@mert.com \\ ${ }^{2}$ Yıldız Teknik Üniversitesi, Fen Bilimleri Enstitüsü, Makine Mühendisliği Anabilim Dalı, Makine Teorisi ve Kontrol Yüksek Lisans Programı İstanbul, Türkiye \\ (ORCID: 0000-0003-4680-7910) berk.basgol@mert.com \\ 3* Yıldız Teknik Üniversitesi, Makine Fakültesi, Makine Mühendisliği Bölümü, İstanbul, Türkiye (ORCID: 0000-0002-9724-3433) mmetin@yildiz.edu.tr \\ ${ }^{4}$ Mert Teknik Fabrika Malzemeleri Ticaret ve Sanayi A.Ş. Ar-Ge Merkezi, İstanbul, Türkiye (ORCID: 0000-0002-2714-9249) timucin.bayram@mert.com
}

(İlk Geliş Tarihi 29 Temmuz 2020 ve Kabul Tarihi 24 Aralık 2020)

(DOI: $10.31590 /$ ejosat.775221)

ATIF/REFERENCE: Taşağıll, G., Başgöl, B., Metin, M. \& Bayram, T. (2020). Elastomer Karakterizasyon Test Sistemlerinin Modellenmesi ve Parametrik Analizleri. Avrupa Bilim ve Teknoloji Dergisi, (20), 881-889.

\section{Öz}

Bu çalışmada, üzerinde elastomer malzeme barındıran burç gibi makine parçalarının statik ya da dinamik karakterizasyon testlerinde kullanılan hidrolik eyleyicili test sistemi modellenmiştir. Burada, literatürde yer alan viskoelastik malzemeler için geliştirilmiş matematiksel modellere sistemin kütle değişkeni de ilave edilerek daha gerçekçi modeller oluşturulmuştur. Daha sonra, viskoelastik malzeme modellerinin hidrolik test sistemi ile birleştirilmesiyle birlikte test sisteminin genel modeli elde edilmiştir. Bu kapsamda, katı ve sıvı viskoelastik modeller ayrı ayrı ele alınmış ve analiz edilmiştir. Parametrik simülasyonlarla yapılan dinamik analizlerde, viskoelastik model parametrelerinin malzeme üzerinde oluşan kuvvet, hız ve yer değiştirme gibi dinamik cevaplara etkileri ortaya konmuştur. Bu çalışmadan elde edilen bilgiler 1şı̆̆ında, malzeme karakterizasyon testlerinden elde edilecek veriler kullanılarak testi yapılan malzmelerin dinamik model parametrelerinin kestirimi ve bunlara ait dinamik model kurulumu daha kolay yapılabilecektir.

\section{Modelling and Simulation of Elastomer Materials Test System}

\begin{abstract}
In this study, hydraulic actuator test system, which is used in static or dynamic characterization tests of machine parts such as bushing with elastomer material, is modeled. Here, more realistic models were created by adding the mass variable of the system to the mathematical models developed for viscoelastic materials in the literature. Then, the general model of the test system was obtained by combining the viscoelastic material models with the hydraulic test system. In this context, solid and liquid viscoelastic models are handled and analyzed separately. In dynamic analysis with parametric simulations, the effects of viscoelastic model parameters on dynamic responses such as force, velocity and displacement on the material have been revealed. In the light of the information obtained from this study, using the data obtained from the material characterization tests, it will be easier to estimate the dynamic model parameters of the tested materials and to set up their dynamic models.
\end{abstract}

Keywords: Viscoelastic Material, Elastomer, Dynamic Characterization, Hydraulic Test System, Servo Valve.

\footnotetext{
* Sorumlu Yazar: Yıldız Teknik Üniversitesi, Makine Mühendisliği Bölümü, İstanbul, Türkiye, ORCID: 0000-0002-9724-3433, mmetin@yildiz.edu.tr
} 


\section{Giriş}

Otomotiv, havacılık veya diğer sektörlerde bulunan makinelerde titreşimin izolasyonu, makine parça ömürlerinin uzatılması, konfor şartlarının sağlanması ve gürültü emisyonunun azaltılması açısından çok önemlidir. $\mathrm{Bu}$ titreşim etkilerini azaltmak için manyetoreolojik damper veya hidrolik eyleyici gibi yarı aktif/aktif kontrol elemanları kullanılabilir. Fakat bu elemanları kullanmak hem sistemi karmaşıklaştıracak hem de toplam sistem maliyetini arttıracaktır. Bu sebeple çoğu zaman elastomer gibi pasif elemanlar ile titreşimin absorbe edilmesi tercih edilir. Fakat kullanılacak elastomerin gerekli şartları sağlayabildiğini tespit edebilmek için kompleks modül ve kayıp faktör gibi malzemenin yapısal özellikleri hakkında bilgi sahibi olmak gereklidir. Bu sebeple, malzeme test edilerek yapısal parametreleri elde edilmeli ve elastomerin matematiksel modeli oluşturulmalıdır. $\mathrm{Bu}$ yapılmadan elastomer malzemenin kullanıldığı sistemin dinamik modeli gerçek duruma yakın olarak oluşturulamaz. Genel sistemin dinamik modeli doğru bir şekilde kurulmadan da yapılacak simülasyonlarla sistemin dinamik cevapların nasıl olacağına dair bir öngörü yapılması mümkün olmaz (Williams, 1964; Popov, Hess ve Willert, 2019; Christensen, 1982; Phan-Thien, 2013).

Elastomer malzemeler aynı anda hem elastik hem de viskoz özellik gösteren malzemelerdir. Bu tür malzemelerin genel adı viskoelastik malzemedir. Temelde katı veya elastik olarak adlandırılan ideal malzemenin özelliği, uygulanan yüke karşı malzemede bir deplasman oluşması ve tepki kuvvetinin bu deplasman ile doğru orantılı olmasıdır. Viskoz olarak bahsedilen ideal malzemelerde ise yüke bağlı bir hız ve bu hız ile doğru orantılı bir tepki kuvveti oluşur. Viskoelastik malzemelerin yük altında hem elastik hem de viskoz özellik göstermeleri iki sonuca sebep olmaktadır; ilki, hız parametresinin de dinamik tepkiyi etkilemesi olup, ikincisi ise bu malzemelerin uzun süre yüke maruz kaldıklarında üzerlerinde kalıcı şekil değişikliğinin oluşmasıdır. Viskoelastik malzemelerin dinamik tepkilerine göre literatürde farklı modeller geliştirilmiştir. $\mathrm{Bu}$ modellerde kullanılan yay elemanları katılıkları, damper elemanları ise viskoz hareketler ile oluşan sönümü temsil eder. Hem katı hem de sıvı özelliği sağlayacak indirgenmiş model, yay ve sönüm elemanlarının çeşitli şekillerde birbirleri ile bağlanarak modellenmesi ile türetilir. Her elastomer malzemenin yapısı ayrı olduğu için oluşturulacak fiziksel ve matematiksel model de farklı olacaktır. Dolayısıyla her viskoleastik malzemeye uygun dinamik modeli geliştirebilmek için karakterizasyon testi yapılmalıdır. (Mainardi, 2010; Flügge, 1975; Ferry, 1980)

Elastomerlerin testi için kullanılan test sistemleri genellikle hidrolik eyleyiciler ile çalışır (Clamroth, 1981). Bunun sebebi, hidrolik sistemlerin yüksek kuvvet değerlerine çıkabilmesi, yüksek frekanslarda çalışabilmeleri ve kontrol edilmelerinin kolay olmasıdır (Dindorf ve Wos, 2019). Güvenilirlik ve yüksek performans seviyeleri sebebiyle servo valfler endüstride ve havacılık gibi kapalı çevrim hassas kontrole ihtiyaç duyan hidrolik sistemlerde sıklıkla kullanılır (Tamburrano ve diğerleri, 2019). Elastomer test sisteminde parça yüksek frekanslara maruz bırakılacağı için standart oransal valfler yerine ihtiyacı karşılayan servo valf kullanılmaktadır (MOOG Industrial Controls Division, 2016). Elastomer malzemenin matematiksel modelini çıkarabilmek için test sistemi malzemeyi belirli yük değerlerinde zorlamalı ve malzemenin bu yüklere olan tepkisini ölçmelidir
[12]. Bunları yapabilmek için test sisteminin, test edilecek parça ile birlikte modellenmesi gerekmektedir.

Viskoelastik malzemelerin testlerinin gerçekleştirildiği sistemlere örnek bir diğer sistemin adı da Dinamik Mekanik Analiz (DMA) cihazıdır. DMA'lar basitçe tanımlanacak olursa, bir deney malzemesine salınımlı deplasman uygulayan ve bu deplasman karşısında oluşan kuvveti izleyen sistemlerdir. $\mathrm{Bu}$ şekilde malzemenin akma eğilimi, faz gecikmesi ve sertlik modülünü çıkartarak dinamik-mekanik analiz yaparlar (Menard, 1999).

DMA cihazları bahsi geçen özellikleri sayesinde malzeme modeli oluştururken tercih edilirler. Lucie Rouleau ve diğerleri 2015 'te yaptıkları çalışmada kendinden yapışkan sentetik kauçuk için DMA analizi gerçekleştirmiştir. Bunu yaparken viskoelastik malzemeyi modellemiş ve yaptığı testler ile oluşturduğu modelleri karşılaştırmıştır. Yüksek frekanstaki malzeme yapısını modellemek için zaman sıcaklık süperpozisyon prensibi uygulanmıştır (Rouleau ve diğerleri, 2015). A. N. Bobryshev ve diğerleri ise 2016'da yaptıkları çalışmada elastik ve viskoz elemanlardan yapılan klasik reolojik modelleri kısaca analiz edip, kompozitlerde bir çeşit viskoelastik gevşeme mekanizması modeli önermiştir (Bobryshev ve diğerleri, 2015).

$\mathrm{Bu}$ çalışmada, literatürde yer alan viskoelastik malzeme modellerine kütle değişkeninin eklenmesi ile elastomer malzeme dinamik karakterizasyon test sistemleri için daha gerçekçi matematiksel modeller elde edilmiştir. Bunlar, servo valf ve diğer hidrolik eyleyici bişleşenleri ile birleştirilerek test sisteminin genel dinamik modeli kurulmuştur. Böylece, otomobil gibi birçok sistemde kullanılan ve üzerine elastomer malzeme barındıran burç benzeri elemanların statik-dinamik karakterizasyonlarını yapacak özel bir test sistemine ait dimamik model çıkartılmıştır. Bu model kullanılarak, testlerde elastomer yapı barındıran makine parçasına uygulanacak kuvvet ile malzeme üzerinde oluşacak yer değiştirme, hız ve kuvvet gibi verilere dair simülasyonlar yapılabilmektedir. Deneysel olarak yapılacak testlerde yer değiştirme gibi sonuç bilgilerinden yola çıkarak model parametresi gibi veriler elde edilirken, bu simülasyon çalışmasında çeşitli malzeme model parametrelerine ait değişimlerin malzeme üzerinde oluşacak yer değiştirme, hız ve kuvvet gibi dinamikleri nasıl etkilediği ortaya konmuştur. Böylece, test sonucunda elde edilecek verilerle kurulacak uygun malzeme modelleri ve yapılacak parametre kestirimleri için temel bilgiler elde edilmiştir.

\section{Elastomer Test Sistemi}

Elastomer test sistemleri viskoelastik özellik gösteren elastomerlerin statik ve dinamik karakterizasyon testleri için kullanılır. Elastomer malzemelerin bu karakteristik özellikleri parçanın tasarım parametreleri olmaktadır. Diğer bir deyişle, elastomer malzeme bir makine parçası olarak kullanılacaksa matematiksel hesaplamalar için parçanın yay katsayısı ve sönüm değerlerine ihtiyaç vardır. $\mathrm{Bu}$ değerler varsa makinelerin modelleri oluşturulabilir ve analizleri yapılabilir (Brown, 2018). 


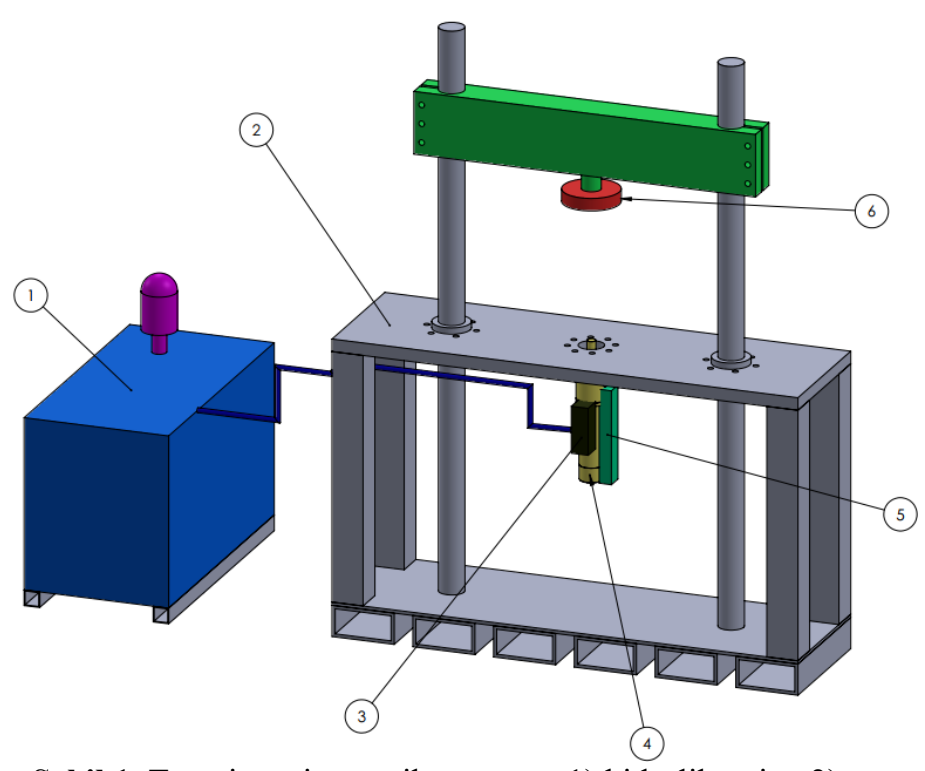

Şekil 1. Test sistemi şematik tasarımı; 1) hidrolik ünite, 2) test sistemi gövdesi, 3) servo valf, 4) hidrolik silindir, 5) lineer cetvel, 6) yük hücresi.

Şekil 1'de test sisteminin elemanları görünmektedir. Test sisteminin çalışma prensibi şu şekilde gerçekleşmektedir: Testi gerçekleştirebilmek için içindeki pompa yardımıyla hidrolik yağ sıkıştırılarak test ekipmanına gönderilir. Sıkışan yağ önce servo valfte ayarlanarak silindire basılır ve silindirde kuvvet ve deplasmana dönüşür. Test yapılacak parça gövdedeki aparatlara bağlanır. Testin güvenilirliği için test sistemi gövdesi mümkün olduğunca rijit olmalıdır. Böylelikle test sisteminin deformasyonu minimize edilecek ve parçada oluşacak deformasyonlar tüm test ekipmanından bağımsız olarak incelenebilecektir. Test sistemi gövdesinin rijitliği ve sisteme uygulanan kontrolün hassas olmas1, parçanın karakteristik değerleri olan sertlik ve sönüm değerlerinin yüksek doğrulukta elde edilmesini sağlayacaktır.

\section{Test Sisteminin Fiziksel ve Matematiksel Modellerinin Çıkarılması}

$\mathrm{Bu}$ bölümde, test sistemine ait alt bileşenlerin modelleri oluşturulmuştur. Öncelikle hidrolik sistemde bulunan servo valf ve hidrolik silindirin fiziksel ve matematiksel modelleri çıkartılmıştır. Daha sonra, elastomer malzeme için yay ve sönüm elemanı modellerin yanı sira, Maxwell modeli, Kelwin-Voigt modeli, Anti-Zener sıv1 modeli ve Zener katı modeli oluşturulmuştur. Oluşturulan bu matematiksel modeller malzemedeki kuvvet ve deplasman ilişkisini ifade eder. Ayrıca, modellere sistemdeki yağın, pistonun ve parçanın kütlesini temsil eden kütle de eklenmiştir.

\subsection{Hidrolik Sistemin Fiziksel ve Matematiksel Modeli}

Hidrolik sistemlerin temel kullanılma sebebi güç iletimini kolaylaştırmalarıdır. Sıkıştırılan akışkanda basınç (kayıplar ihmal edilirse) tüm akışkan içinde eşit olarak yayılacaktır. Bu sebeple güç iletimi basıncı muhafaza ederek çok kolay sağlanır. Hidrolik sistemlerde akışkan olarak hidrolik yağ kullanılmaktadır. Bu yă pompa ile sıkıştırılarak borular yardımı ile hidrolik motor veya silindirlere gönderilir ve burada hidrolik güç mekanik güce dönüştürülür (Manring ve Fales, 2020).
Hidrolik yă̆ tank1,

Pompa,

Hidrolik devre elemanları (Valfler, filtreler, akü, vb.),

Eyleyiciler.

Elastomer testi için kullanılan hidrolik sistemde eyleyici girişi servo valf ile sağlanır. Bunun sebebi, servo valfin tepki süresinin 5-20 ms aralığında olması ve çok hassas kontrollere izin vermesidir (MOOG Industrial Controls Division, 2016). Servo valflerin stabil çalışması için giriş basınçları sabit tutulmalıdır. $\mathrm{Bu}$ sebeple tasarlanan hidrolik sistemin tamamı valf girişinde sabit basınç elde edecek şekilde dizayn edilecektir. Hidrolik sistemde bulunan valf ve silindir hariç diğer ekipmanları modellemek yerine, servo valf girişinde sabit basınç, servo valf ve eyleyici olarak modellemek hem gerçeğe uygun sonuçlar verecek hem de hidrolik matematiksel model kurmayı basitleştirecektir. Şekil 2'de bahsi geçen fiziksel model gösterilmiştir.

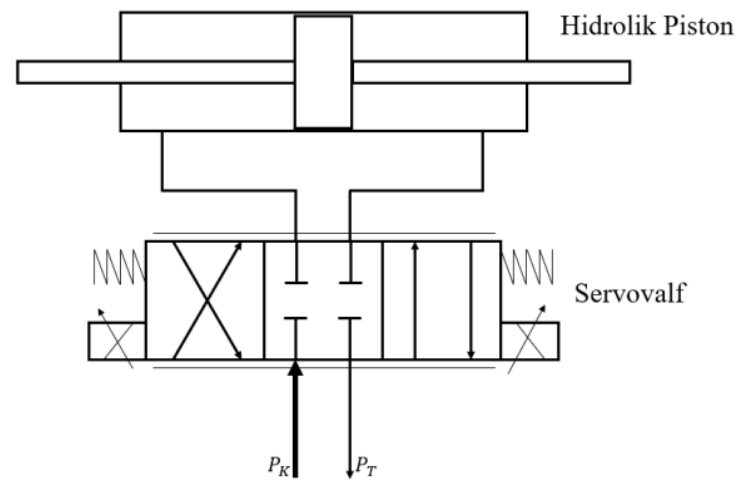

Şekil 2. Basitleştirilmiş hidrolik model (Rydberg, 2016).

Burada $P_{K}$ hidrolik sistemden gelen kaynak basıncını, $P_{T}$ ise silindir çıkışından tanka dönen hattaki tank basıncını göstermektedir. Yük basıncı yanında tank basıncı düşük kalacağı için işlem kolaylığı açısından tank basıncı ihmal edilebilir.

\subsubsection{Servo Valf Modeli}

Servo valf akış denklemi (1)'deki gibidir (Manring ve Fales, 2020);

$$
Q(t)=C_{v} w d(t) \sqrt{\frac{2 \Delta P}{\rho}}
$$

Burada $Q$ valften geçen debi miktarı, $C_{v}$ valf boşaltma katsayısı, $w$ valfin sürgüsünün çevre uzunluğu, $d$ sürgünün hareket miktarı ve $\rho$ yağın yoğunluğudur. $\Delta P$ ise valf içinde sürgüde oluşan orfisin giriş ve çıkışı arasında oluşan basınç düşümüdür. Servo valfin girişinde sabit $P_{K}$ kaynak basıncı ve çıkışında ise eyleyiciden gelen yükün oluşturduğu $P_{Y}$ yük basıncı olacaktır. Bu sebeple basınç düşümü (2)'deki gibidir;

$$
\Delta P=P_{K}-P_{Y}
$$

Ticari olarak satılan servo valflerde her valfin tam sürgü açıklığı için değişken basınç düşümlerinde geçirdikleri debi miktarı Şekil 3 'teki gibi ve ayrıca sürgü konumunun dolayısı ile debinin uygulanan giriş sinyaline doğrusal bağlı olduğu (merkez konum dışında) grafiksel olarak gösterilmiştir. Bu bilgilerden yola çıkarak akış denklemi (3)'teki gibi sadeleştirilebilir;

Hidrolik sistem temel olarak şu kısımlardan oluşmaktadır; 


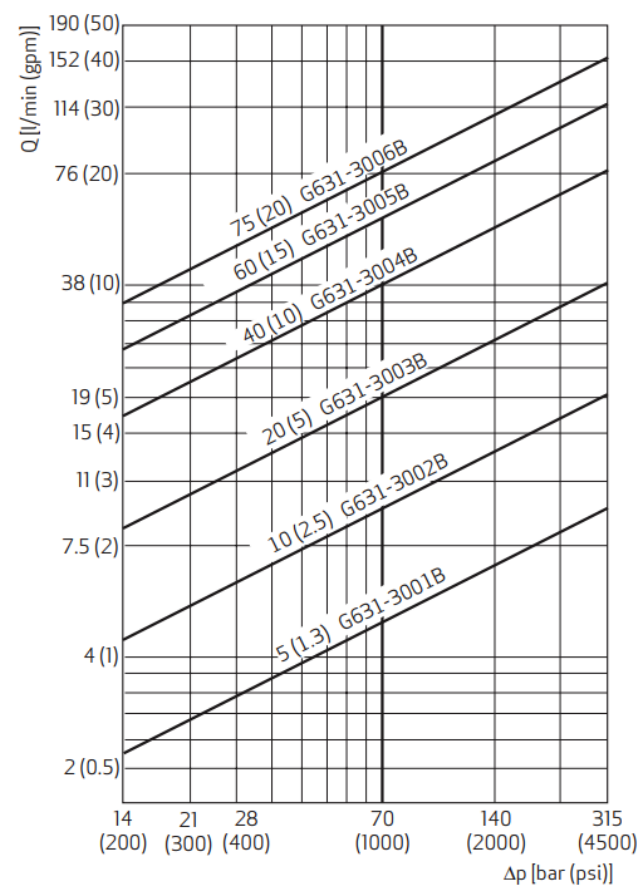

Şekil 3. MOOG Servo valf basınç düşümü-debi grafiği (MOOG, 2018).

$$
Q(t)=K_{v} \% u \sqrt{\Delta P}
$$

Burada \%u servo valfe uygulanan giriş sinyal yüzdesini, $K_{v}$ ise valf üreticisinin verdiği değerdir. $K_{v}$ değeri grafikten (4)'teki denklem yardımı ile bulunabilir.

$$
K_{v}=\frac{Q_{N}}{\sqrt{\Delta P_{N}}}
$$

$Q_{N}$ grafikteki 70 bar $\Delta P_{N}$ 'ye denk gelen debi miktarıdır.

\subsubsection{Hidrolik Silindir Modeli}

Çift etkili silindirlerde yük haznesi ile tank haznesi alanı eşittir (Şekil 4). Bu tip silindirlerin gidiş ve dönüş hareketlerinde aynı kuvvet ve hızlara ulaşmalarını sağlamak alan eşitliğinden dolayı daha kolay olacaktır.

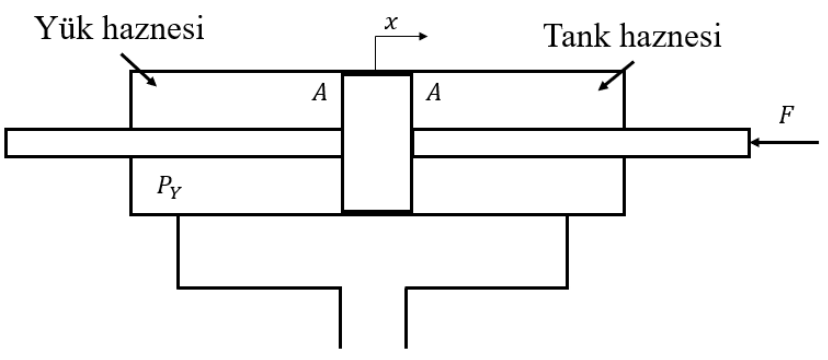

Şekil 4. Çift etkili hidrolik silindir modeli (Manring ve Fales, 2020).

Hidrolik silindirin hareketi silindire giren yağın hacmi ile, silindirin hızı ise yağın debisi ile oluşacaktır. Giren debiye bağlı olarak oluşacak basınç denklemi ise (5)'te gösterilmiştir.

$$
\frac{v_{0}}{\beta} \dot{P}_{Y}=Q(t)-A \dot{x}-C_{L} P_{Y}
$$

Yük haznesinde oluşacak basınç yük kuvvetinden kaynaklı (6)'daki gibi olacaktır.

e-ISSN: 2148-2683

$$
P_{Y}=\frac{F}{A}
$$

Burada $A$ silindir alanı, $v_{0}$ yük haznesi ilk hacmi, $\beta$ yağın bulk modülü ve $C_{L}$ sızdırma katsayısıdır. Bulk modülü yağın sıkışma değeri olup birimi MPa'dır. Sızdırma katsayısı ise piston içinde yük haznesinden diğer hazneye ve dişarıya akan kayıp yağı modellemek için kullanılan değerdir (Vietor, Lukjanec ve Balint, 2016).

\subsection{Elastomerlerin Fiziksel ve Matematiksel Modelleri}

Bir yay üzerine belirli bir $F$ kuvveti uygulandığında, yay belirli bir $x$ miktarı kadar sıkışacak veya uzayacaktır. Kuvvet kaldırıldığında ise yay eski konumuna geri dönecektir. Bahsi geçen bu özelliğe elastiklik denmektedir. Bu ilişkiyi matematiksel olarak yazacak olursak (7)'deki denklem elde edilir (Mainardi, 2010).

$$
F=k x
$$

Burada $k$ yay katsayısı olup lineer olduğu varsayılmıştır.

Yağ dolu bir hazne içinde hareket eden silindir bir sönüm elemanı oluşturur. Yağın viskozitesinden dolayı silindiri hareket ettirmek için bir kuvvet gerekecektir. Kuvvetin şiddeti artacak olursa silindirin hızında da artma olacak ve silindirin gittiği mesafeden bağımsız fakat hızına bağlı bir ilişki oluşacaktır. Bu ilişki ile lineer (8)'deki denklem kurulur.

$$
F=c \dot{x}
$$
2010).

Burada $c$ viskoz etkinin indirgendiği bir katsayıdır (Mainardi,
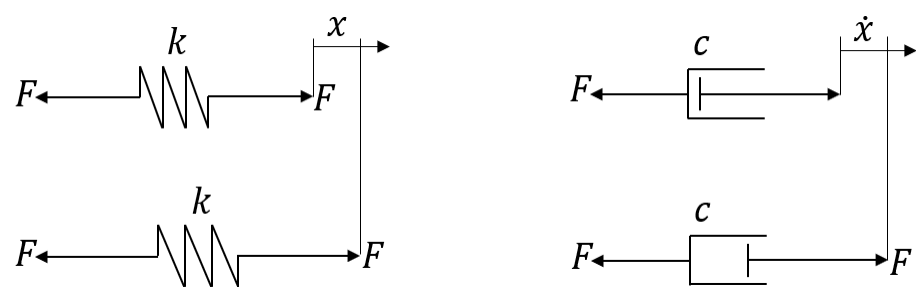

Şekil 5. Yay ve sönüm modelleri (Mainardi, 2010).

Şekil 5'te kuvvet ve deplasman arasındaki ilişki sembolik olarak gösterilmiştir. Elastomer malzemeler viskoelastik özellik gösteren malzemelerdir. Viskoelastik malzemeler ise uygulanan yük altında hem viskoz hem de elastik özellik göstermektedir. Bu özellik yay ve sönüm elemanlarının çeşitli şekillerde birbirleri ile bağlanmasıyla modellenebilir.

\subsubsection{Maxwell Modeli}

Şekil 6'daki Maxwell modelinde yay ve sönüm seri bağlanmıştır. Yük altında bu model sürekli deformasyona izin verecektir. Yük ortadan kalktığında ise kalıcı deformasyon oluşacaktır. Kalıcı deformasyona izin veren modellere aynı zamanda sıvı modeller de denmektedir. Kuvvet deplasman ilişkisi (9)'daki gibidir (Mainardi, 2010). 


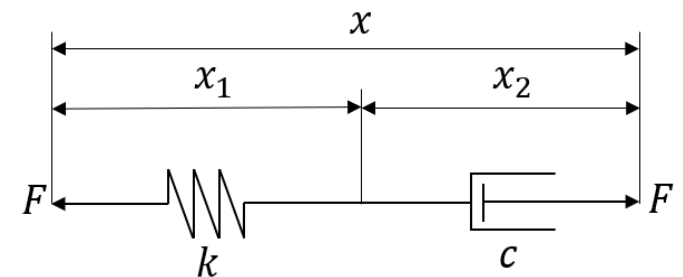

Şekil 6. Maxwell modeli (Mainardi, 2010).

$$
\begin{gathered}
x=x_{1}+x_{2} \\
F=k x_{1}, \quad F=c \dot{x}_{2} \\
\dot{x}=\frac{\dot{F}}{k}+\frac{F}{c}
\end{gathered}
$$

Maxwell modeline sistem kütlesi eklendiğinde Şekil 7'deki fiziksel model elde edilir. Bu modelin matematiksel denklemi ise (10)'daki gibi olur.

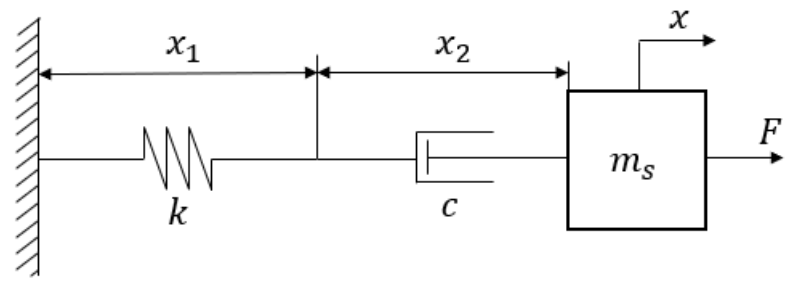

Şekil 7. Kütleli Maxwell modeli.

$$
\frac{\dot{F}}{k}+\frac{F}{c}=\dot{x}+\frac{m}{c} \ddot{x}+\frac{m}{k} \dddot{x}
$$

\subsubsection{Kelvin-Voigt Modeli}

Sekil 8'deki Kelvin-Voigt modelinde yay ve sönüm elemanı paralel bağlanmıştır. Bu model yük altında sürekli deformasyona izin vermeyecek ve deformasyonu yükün şiddetine göre limitleyecektir. Ayrıca yük ortadan kalktığında kalıcı deformasyon da oluşmayacaktır. Bu tür malzemeler katı özellik gösteren malzeme olarak da adlandırılırlar. Kuvvet deplasman ilişkisi (11)'deki gibidir (Mainardi, 2010).

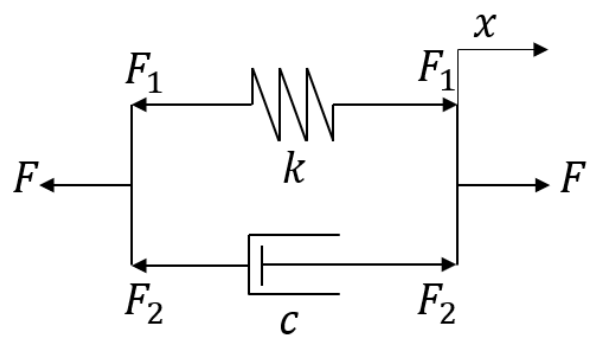

Şekil 8. Kelvin-Voigt modeli (Mainardi, 2010).

$$
\begin{gathered}
F=F_{1}+F_{2} \\
F_{1}=k x, \quad F_{2}=c \dot{x} \\
F=k x+c \dot{x}
\end{gathered}
$$

Kelvin-Voigt modeline sistem kütlesi eklendiğinde Şekil 9'daki fiziksel model elde edilir. Bu modelin matematiksel denklemi ise (12)'deki gibi olur.

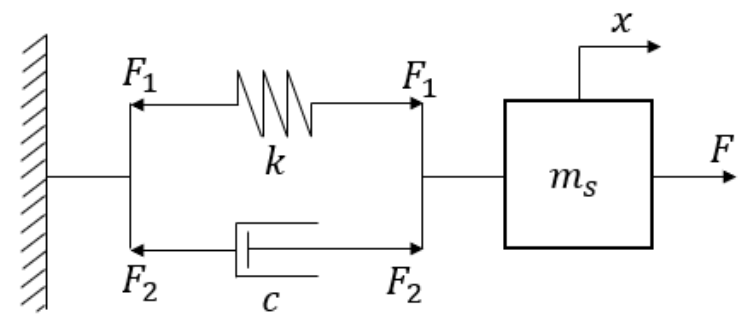

Şekil 9. Kütleli Kelvin-Voigt modeli.

$$
F=k x+c \dot{x}+m \ddot{x}
$$

\subsubsection{Anti-Zener Sivv Modeli}

Şekil 10'daki Zener modeli aynı zamanda üç elemanlı model olarak bilinmektedir. Üç elemanlı modellerde Kelvin-Voigt modeline seri olarak yay veya sönüm elemanı eklenir. Yay eklenirse toplam model katı özellik gösterirken, sönüm eklenirse sıv1 özellik gösterecektir. Kuvvet deplasman ilişkisi (13)'teki gibidir (Mainardi, 2010).

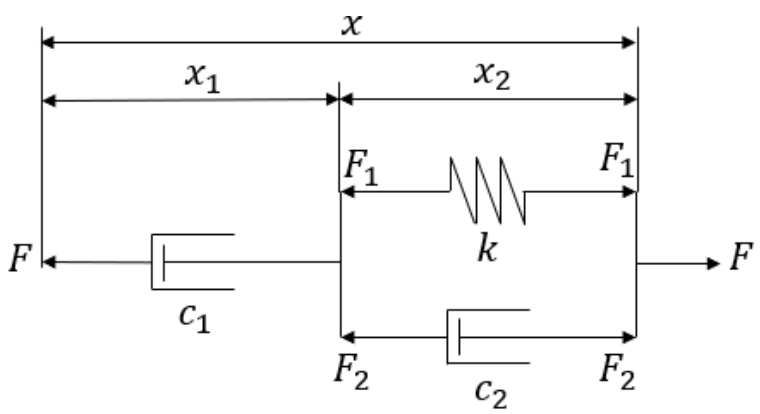

Şekil 10. Anti-Zener sıv1 modeli (Mainardi, 2010).

$$
\begin{gathered}
F=c_{1} \dot{x}_{1}, \quad F=F_{1}+F_{2}=k x_{2}+c_{2} \dot{x}_{2} \\
x=x_{1}+x_{2} \\
F+\frac{\left(c_{1}+c_{2}\right) \dot{F}}{k}=\frac{c_{1} c_{2}}{k}\left(\ddot{x}+\frac{k \dot{x}}{c_{2}}\right)
\end{gathered}
$$

Anti-Zener sıvı modeline sistem kütlesi eklendiğinde Şekil 11'deki fiziksel model elde edilir. Bu modelin matematiksel denklemi ise (14)'teki gibi olur.

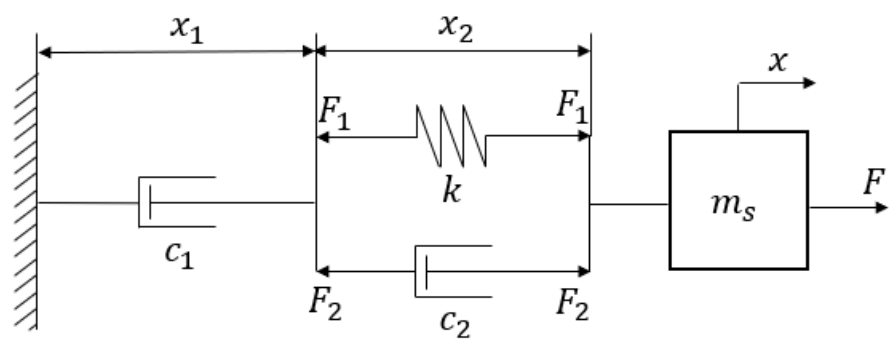

Şekil 11. Kütleli Anti-Zener sıvı modeli.

$$
\begin{aligned}
F+\frac{\left(c_{1}+c_{2}\right) \dot{F}}{k}= & c_{1} \dot{x}+\frac{c_{1} c_{2}+m k}{k} \ddot{x} \\
& +\frac{\left(c_{1}+c_{2}\right) m}{k} \dddot{x}
\end{aligned}
$$

\subsubsection{Zener Katı Modeli}


Şekil 12'deki Zener modeli aynı zamanda üç elemanlı model olarak bilinmektedir. Üç elemanlı modellerde Kelvin-Voigt modeline seri olarak yay veya sönüm elemanı eklenir. Yay eklenirse toplam model katı özellik gösterirken, sönüm eklenirse sıvı özellik gösterir. Kuvvet deplasman ilişkisi (15)’teki gibidir (Mainardi, 2010).

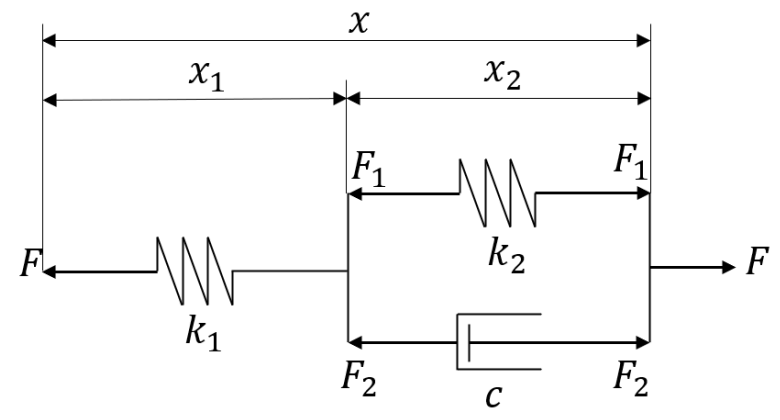

Şekil 12. Zener katı modeli (Mainardi, 2010).

$$
\begin{aligned}
F=k_{1} x_{1}, \quad F & =F_{1}+F_{2}=k_{2} x_{2}+c \dot{x}_{2} \\
x & =x_{1}+x_{2} \\
F+\frac{c \dot{F}}{k_{1}+k_{2}} & =\frac{k_{1} k_{2}}{k_{1}+k_{2}}\left(x+\frac{c \dot{x}}{k_{2}}\right)
\end{aligned}
$$

Zener katı modeline sistem kütlesi eklendiğinde Şekil 13'teki fiziksel model elde edilir. Bu modelin matematiksel denklemi ise (16)'daki gibi olur.

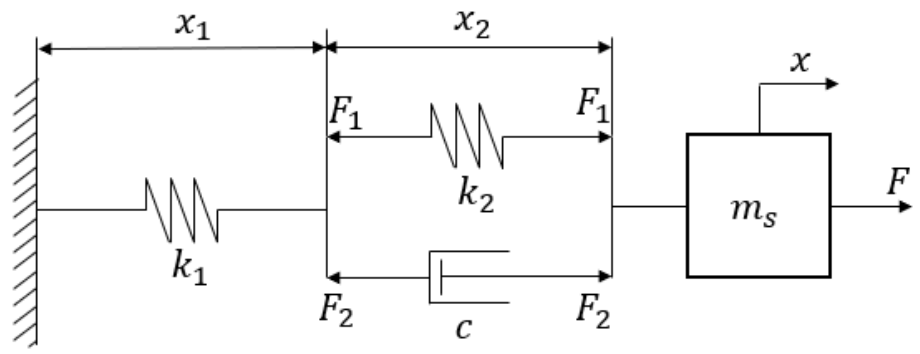

Şekil 13. Kütleli Zener katı modeli.

$$
\begin{gathered}
F+\frac{c \dot{F}}{k_{1}+k_{2}}=\frac{k_{1} k_{2}}{k_{1}+k_{2}} x+\frac{k_{1} c}{k_{1}+k_{2}} \dot{x}+m \ddot{x} \\
+\frac{c m}{k_{1}+k_{2}} \dddot{x}
\end{gathered}
$$

\section{Simülasyon}

Bu bölümde bahsi geçen matematiksel modellerde Tablo 1'de belirtilen parametreler kullanılarak MATLAB - Simulink yazılımı ile simülasyon çalışmaları yapılmıştır. Katı ve sıvı modellerde ilave parametrenin değişiminin etkisi izlenmek için bu parametre farklı değerlerde alınıp servo valfe \%10'luk $(\% u=0,1$ veya $u=10 \mathrm{~mA})$ giriş sinyali (Şekil 14) uygulanarak elastomer malzeme üzerinde oluşan kuvvet, yer değiştirme ve hız cevaplarını incelemek amacıyla simülasyonlar gerçekleştirilmiş ve elde edilen sonuçlar karşılaştırılmıştır.

\begin{tabular}{|c|c|c|c|c|c|}
\hline Değişkenler & Birim & Maxwell Modeli & Kelvin-Voigt Modeli & Anti-Zener Sivi Modeli & Zener Katı Modeli \\
\hline$P_{K}$ & bar & 100 & 100 & 100 & 100 \\
\hline$\% u$ & $\mathrm{~mA}$ & 0,1 & 0,1 & 0,1 & 0,1 \\
\hline$\beta$ & $\mathrm{MPa}$ & 1800 & 1800 & 1800 & 1800 \\
\hline$A$ & $\mathrm{~m}^{2}$ & 0,0137 & 0,0137 & 0,0137 & 0,0137 \\
\hline$v_{0}$ & $\mathrm{~m}^{3}$ & 0,016 & 0,016 & 0,016 & 0,016 \\
\hline$K_{v}$ & - & $4,7 \cdot 10^{-7}$ & $4,7 \cdot 10^{-7}$ & $4,7 \cdot 10^{-7}$ & $4,7 \cdot 10^{-7}$ \\
\hline$C_{L}$ & - & $1.10^{-12}$ & $1.10^{-12}$ & $1.10^{-12}$ & $1.10^{-12}$ \\
\hline$m_{s}$ & $\mathrm{~kg}$ & 30 & 30 & 30 & 30 \\
\hline$k$ & $\mathrm{~N} / \mathrm{m}$ & $1.10^{8}$ & $1.10^{9}$ & $1.10^{8}$ & - \\
\hline$k_{1}$ & $\mathrm{~N} / \mathrm{m}$ & - & - & - & $\begin{array}{c}k_{11}=0,2 \cdot 10^{9} \\
k_{12}=1 \cdot 10^{9} \\
k_{13}=1,4 \cdot 10^{9}\end{array}$ \\
\hline$k_{2}$ & $\mathrm{~N} / \mathrm{m}$ & - & - & - & $1.10^{9}$ \\
\hline$c$ & $\mathrm{Ns} / \mathrm{m}$ & $1.10^{8}$ & $5.10^{5}$ & - & $5.10^{5}$ \\
\hline$c_{1}$ & $\mathrm{Ns} / \mathrm{m}$ & - & - & $1.10^{8}$ & - \\
\hline$c_{2}$ & $\mathrm{Ns} / \mathrm{m}$ & - & - & $\begin{array}{c}c_{21}=0,5 \cdot 10^{8} \\
c_{22}=1 \cdot 10^{8}\end{array}$ & - \\
\hline
\end{tabular}

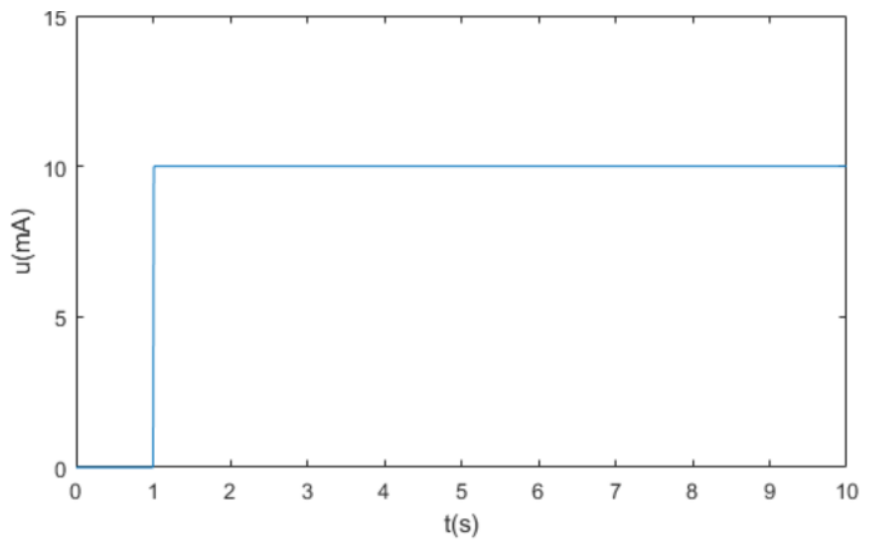

Şekil 14. Giriş sinyal

Tablo 1. Simülasyonda kullanılan fiziksel model parametreleri (Dindorf ve Wos, 2019; MOOG, 2018; Vietor, Lukjanec ve Balint, 2016). 
\begin{tabular}{|l|l|l|l|l|l|}
\hline & & & & $c_{23}=1,5,10^{8}$ & \\
\hline
\end{tabular}

\subsection{Sıvı Model Simülasyonu}

Maxwell ve Anti Zener modelleri sıvı modellerdir. Anti Zener modelinde Maxwell modeline ek olarak $k$ katsayılı yaya paralel bir $\quad c_{2}$ katsayılı sönüm elemanı eklenmiştir. Yapılan simülasyonlarda Anti Zener modellerindeki $c_{2}$ parametresi sirasi ile Anti Zener 1,2,3 için $c_{21}, c_{22}, c_{23}$ değerleri olacak şekilde ele alınmış ve elastomer malzemede oluşan kuvvet, yer değiştirme ve hız cevapları karşılaştırmalı olarak incelenmiştir.

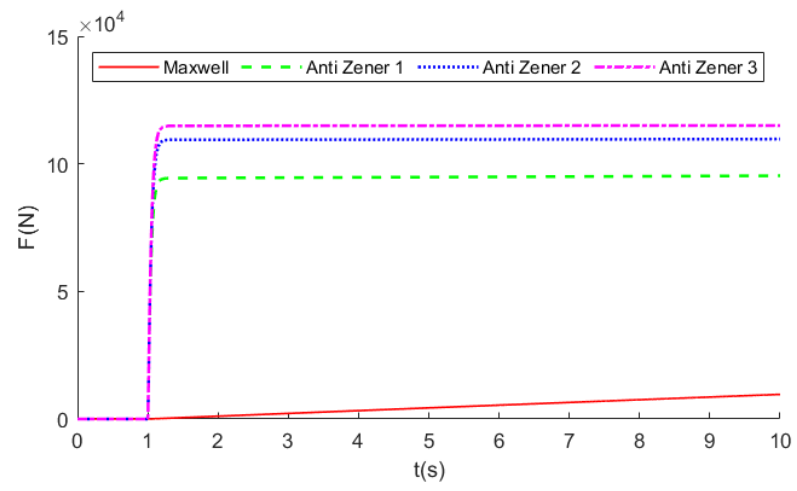

Şekil 15. Sivı modellerin kuvvet cevap kıyasları.

Şekil 15 'te eklenen $c_{2}$ parametresinin modelinin kuvvet cevabında büyük farklılıklar oluşturduğu gözlemlenmektedir. $c_{2}=0$ olarak alınırsa Maxwell modelinin kendisi elde edilir.

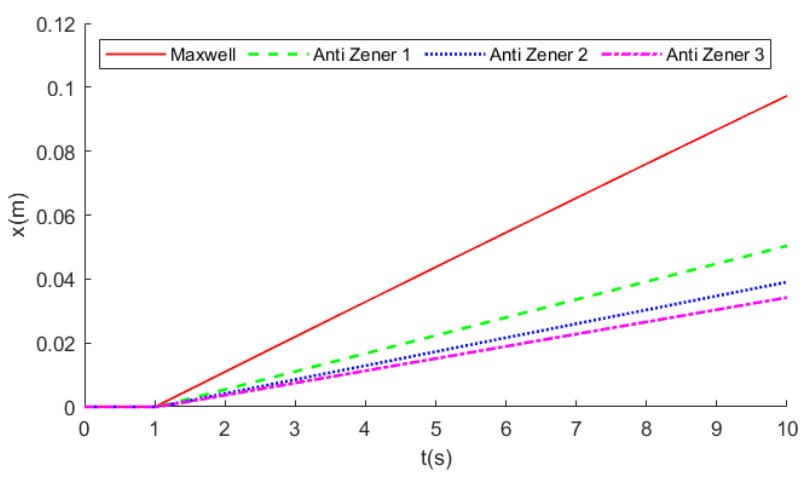

Şekil 16. Sıvı modellerin konum cevap kıyasları.

Şekil 16'da eklenen $c_{2}$ parametresinin arttırılması ile modelinin konum cevabının azaldığı gözlenmektedir. Sıvı model diye tabir edilen modellerde uygulanan kuvvetin sistem üzerinde kalıcı bir hız cevabı oluşturmasından ötürü modellere ait tüm konum cevapları da zamanla artmaktadır.

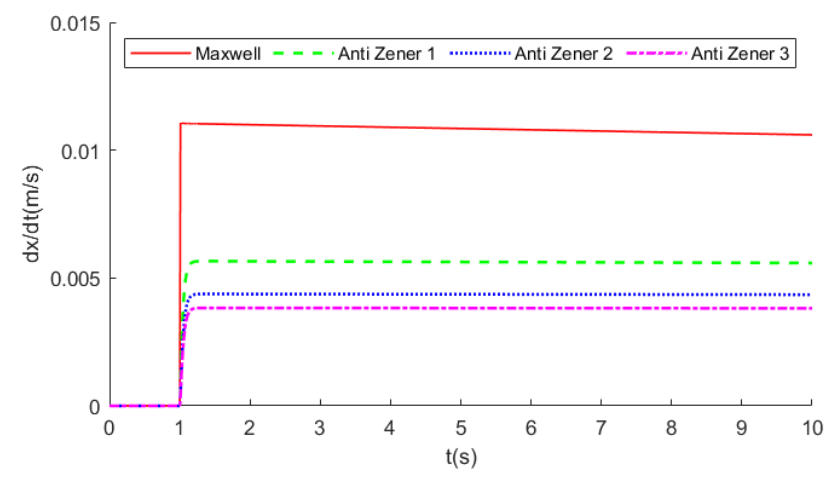

Şekil 17. Sıvı modellerin hız cevap kıyasları.

Şekil 17'de eklenen $\boldsymbol{c}_{\mathbf{2}}$ parametresinin arttırılması ile modelinin hız cevabını azaldığı gözlenmektedir. Sıvı modellerin hızı sistemin uygulanan kuvvetiyle doğru ve toplam sönüm değeriyle ters orantılıdır. Sistem cevabında toplam hızın azalması etkili sönüm değerinin arttığını göstermektedir.

\subsection{Katı Model Simülasyonu}

Viskoelastik malzeme modeli olarak geliştirilen Kelvin-Voigt ve Zener modelleri katı modellerdir. Zener modelinin KelvinVoigt modelinden farkı modele ek seri bağlanmış $\boldsymbol{k}_{\mathbf{1}}$ yayıdır. Yapılan simülasyonlarda Zener modeli içindeki $\boldsymbol{k}_{\mathbf{1}}$ parametresi sırası ile Zener $1,2,3$ 'de $\boldsymbol{k}_{\mathbf{1 1}}, \boldsymbol{k}_{\mathbf{1 2}}, \boldsymbol{k}_{\mathbf{1 3}}$ değerleri olacak şekilde simüle edilmiş ve sonuçlar gözlemlenmiștir.

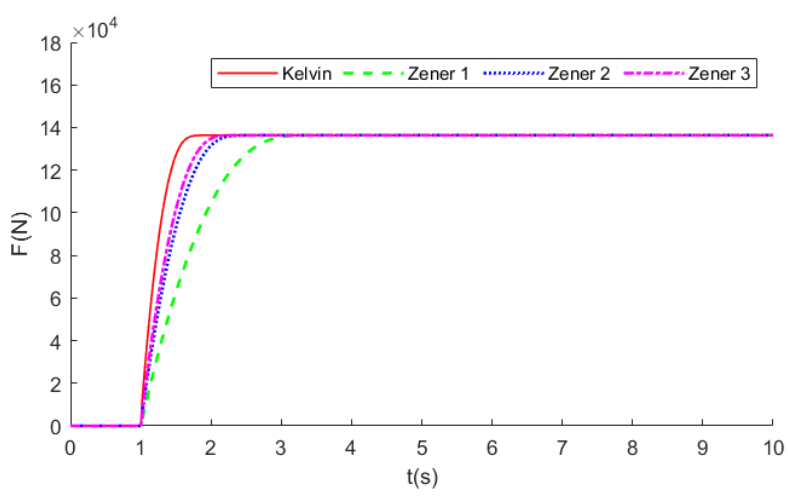

Şekil 18. Katı modellerin kuvvet cevap kıyasları.

Kuvvet cevapları karşılaştırıldığında (Şekil 18) modele ek gelen yay, sistemin rijitliğini azaltmaktadır. Ĕger, bu parametrenin değeri, $k_{1}=0$ olursa bu model Kelvin-Voigt modeline dönüşür, ancak aynı zamanda zemin ile bağı da kopmuş olur, salınım hareketi yapmadan doğrusal bir hareket sergiler. Tam tersi düşünülecek olursa, $k_{1}$ değeri sonsuz olduğunda rijitlik de sonsuz olacak, $k_{1}$ yayı zemin vazifesi görecek ve hem modelin zemin ile bağı kopmayacak hem de model böylece Kelvin-Voigt modeline dönüşecektir. Şekil 18-20 incelendiğinde $k_{1}$ rijitliği arttıkça Zener modelinin Kelvin-Voigt modeline benzemeye başladığı görülebilir. 


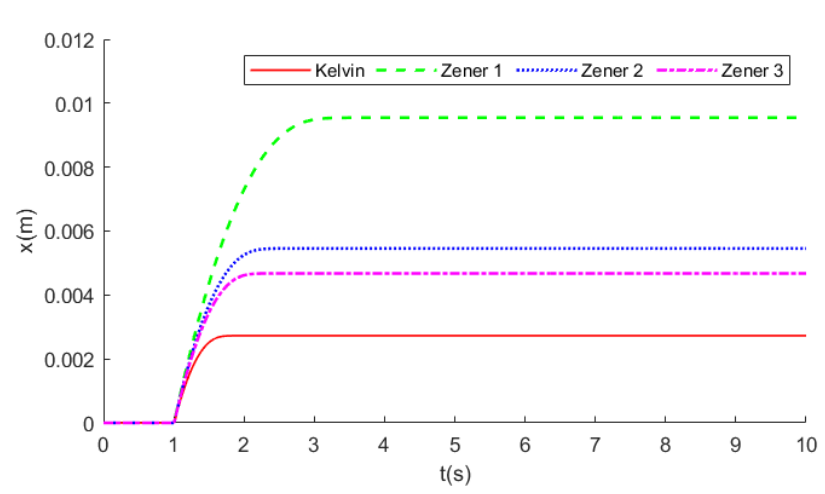

Şekil 19. Katı modellerin konum cevap kıyasları.

Konum cevaplarının (Şekil 19) zamanla bir limite ulaşmasının sebebi modelin katı olmasındandır. Model kalıcı şekil değişimine izin vermeyecek ve kararlı durumda belirli bir deplasmana ulaşacaktır. $k_{1}$ sistemin rijitliğini azalttı̆̆ için modele gelen kuvvete göre oluşacak deplasman değerini arttırmıştır.

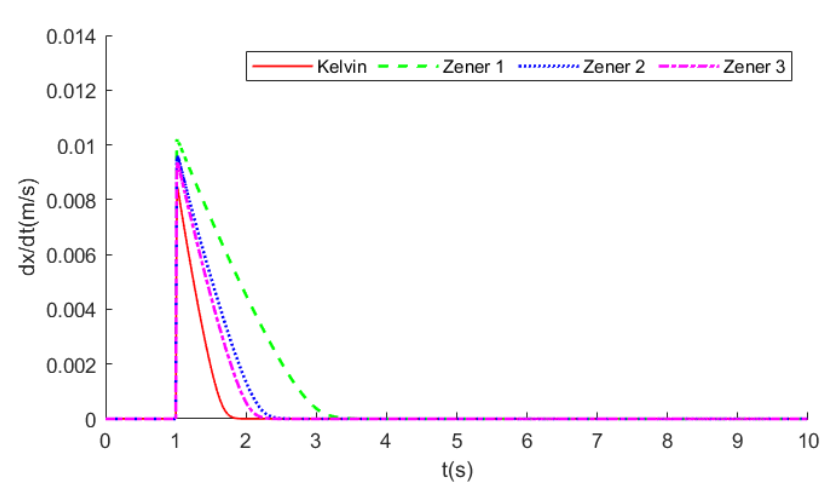

Şekil 20. Katı modellerin hız cevap kıyasları.

Elastomer malzeme üzerinde oluşan hız (Şekil 20) $\boldsymbol{k}_{\mathbf{1}}$ parametresi eklendiğinde, sistemin eşdeğer rijitliği azaldığı için artmıştır. $\boldsymbol{k}_{\mathbf{1}}$ değeri arttıkça rijitlik artacak, bu sebeple elastomer üzerinde oluşan hız azalacak ve model Kelvin-Voigt modeline benzeyecektir.

\section{Sonuç}

Bu çalışmada servo hidrolik eyleyici ile çalışan elastomer test sistemi matematiksel modeli oluşturulmuştur. Öncelikle hidrolik sistemin matematiksel modeli kurulmuştur. Elastomer için kullanılan literatürdeki modellerle birlikte hidrolik model birleştirilerek simülasyon yapılmıştır. Yapılan simülasyonda katı modeller ve sıvı modeller kendi içlerinde karşılaştırılmıştır. $\mathrm{Bu}$ karşılaştırmada, model değişimleri ile ilave edilen parametreler değiştirilerek bunların dinamik cevaplara etkileri incelenmiştir. Katı modelde gelen ek yayın sistemin rijitliğini azalttığ gözlenmiştir. Sıvı modellerde ise, zamanla deplasman değişikliği devam ettiği için ek parametre değişiminin sistemin rijitliği yerine cevap hızını değiştirmektedir.

Yapılan bu simülasyonlar sonucu malzeme modellenirken, test sonuçlarına göre hangi modelin daha uygun olacağ belirlenebilir. Genelde parçalar katı olarak modellense de elastomer gibi kalıcı şekil değişikliğinin düşük yükler altında da oluşabildiği parçalarda katı modele ek olarak yüksek sönüme sahip bir sönüm elemanı eklenerek modellenmesi statik karakterizasyon testleri için daha uygun sonuçlar verecektir.
Dinamik veya salınımlı yükler altında ise parça denge konumu etrafinda zorlanırsa kalıcı şekil değişikliği gözlemlenmeyecek bu sebeple katı model kullanımı yeterli olacaktır.

Gerek sıvı gerekse katı davranış gösteren viskoelastik malzemelerin gerçek davranışlarını ortaya koyan model geliştirebilmek için önceki bölümlerde bahsedildiği gibi literatürde çeşitli modeller mevcuttur. Bu modeller, yay ya da sönüm elemanları ile daha fazla elemanlı modeller haline dönüştürüldükçe daha gerçekçi modellere ulaşmak mümkün olacaktır, ancak bu sefer de modelde tespit edilmesi gereken parametre sayısı artmış olacaktır. Bu çalışmada, Kelvin-Voigt modeline seri bağlanan bir sönüm elemanı eklenmesi ile elde edilen Anti Zener modeli ve Kelvin-Voigt modeline seri bağlanan yay elemanı eklenmesi ile elde edilen Zener modeli ele alınmıştır. Anti Zener modeli yine sıvı nitelik gösteren viskoelastik malzemeler için geliştirilmiş en basit model olan Maxwell modeli ile karşışatırılmış, Zener modeli ise katı nitelik gösteren viskoelastik malzemeler için geliştirilmiş en basit model olan Kelvin-Voigt modeli ile karşılaştırılmıştır. $\mathrm{Bu}$ malzeme modellerinin her biri hidrolik sisteme entegre genel sistem modeli ile simüle edilmiştir. Sıvı nitelikli malzemeler için ele alınan modellerde ilave parametrelere ait değerlerinin artması ile Maxwell modelinden uzaklaşma gözlemlenmiş, katı nitelikli malzemeler için ele alınan modellerde ise ilave parametrelere ait değerlerinin artması ile Kelvin-Voigt modeline yakınlaşma gözlemlenmiştir. Böylece, sıvı davranış gösteren viskoelastik malzeme için ilave parametre değerinin artırılması, katı davranış gösteren malzeme içinse ilave parametre değerinin azaltılması ile dinamik cevapların literatürde yer alan iki parametreli Maxwell ve Kelvin-Voigt modellerinin ürettiği cevaplardan daha esnek ve farklı olarak elde edilebileceği anlaşılmıştır.

$\mathrm{Bu}$ analizler neticesinde elde edilen bilgiler 1şığında, elastomer malzemelerin dinamik karakterizasyonunu tayin etmek için yapılacak testler ile elde edilecek cevaplar kullanılarak en uygun elastomer malzeme modeli oluşturulabilecektir. Böylece, burç gibi elastomer malzeme içeren bileşenlerin doğru dinamik karakterde modellenmesi sağlanacaktır. Bu elemanların içinde bulunduğu taşıt gibi genel sistemlerin tasarım aşamasında modellenerek, simülasyon ve analizlerinin doğru yapılabilmesine imkan sağlanacaktır.

\section{Teşekkür}

$\mathrm{Bu}$ makale, 126 karar numaralı ve "Nonlineer Yapısal Malzemelerin Dinamik-Mekanik Karakterizasyonu İçin Komple Test Sistemi ve Kontrol Algoritması" başlıklı KOSGEB projesi kapsamında Mert Teknik Fabrika Malzemeleri Ticaret ve Sanayi A.Ş. Ar-Ge Merkezi imkanları kullanılarak yazılmıştır.

\section{Kaynakça}

Williams, M.L. (1964), Structural Analysis of Viscoelastic Materials, AIAA Journal, 5(2), 785-808.

Popov, V. L., Hess, M., ve Willert, E. (2019), Handbook of Contact Mechanics Exact Solutions of Axisymmetric Contact Problems, Berlin: Springer.

Christensen, R. M. (1982), Theory of Viscoelasticity Second Edition, New York: Dover Publications. 
Phan-Thien, N., (2013), Understanding Viscoelasticity An Introduction to Rheology Second Edition, New York: Springer.

Mainardi, F., (2010), Fractional Calculus and Waves in Linear Viscoelasticity, London: Imperial College Press.

Flügge W. (1975), Viscoelasticity: Second Revised Edition, Berlin: Springer-Verlag.

Ferry, J. D., (1980), Viscoelastic Properties of Polymers, New York: Jhon Wiley \& Sons.

Clamroth, R. (1981), Determination of Viscoelastic Properties by Dynamic Testing, Polymer Testing, 2, 263-286.

Dindorf, R., Wos, P., (2019), Force and Position Control of The Integrated Electro-Hydraulic Servo-Drive, IEEE.

Tamburrano, P., Plummer, A. R., Distaso, E., Amirante, R. (2019), A Review of Electro-Hydraulic Servovalve Research and Development, International Journal of Fluid Power, 20, 1, 53-98.

MOOG Industrial Controls Division, (2016), Electrohydraulic Valves - A Technical Look[Broşür], http://www.moogvalves.com/Global/FileLib/EH/MoogServoValves-Techn_Look-Overview-en.pdf.

Dautsches Institut Fur Normung (1990), Determination of Viscoelastic Properties of EIastomers(DIN Standart No. 53513:1990-03), https://www.beuth.de/de/norm/din53513/1519202.

Menard, K. P. (1999), Dynamic Mechanical Analysis A Practical Introduction, London: CRC Press.

Rouleau, L., Pirk, R., Pluymers, B., Desmet, W. (2015), Characterization and Modeling of the Viscoelastic Behavior of a Self-Adhesive Rubber Using Dynamic Mechanical Analysis Tests, J. Aerosp, 2(7), 200-208.

Bobryshev, A. N., Lakhno, A. V., Voronov, P. V., Galimov, E. R., Sharafutdinov, R. F., Galimova, N. Y., (2015), New approaches for evaluating rheological models in composites, Materials Science and Engineering, 86 (2015) 012001.

Brown, R., (2018), Physical Test Methods for Elastomers, Cham: Springer.

Manring, N. D., Fales, R. C., (2020), Hydraulic Control Systems Second Edition, John Wiley \& Sons

Rydberg, K. E. (2016), Hydraulic Servo Systems Dynamic Properties and Control, Linköping University: Department of Management and Engineering.

MOOG (2018), Servo Valves Pilot Operated Flow Control Valve with Analog Interface G631/631[Broşür], https://www.moog.com .

Vietor, A., Lukjanec, D., Balint, Z. (2016), Detection of Hydraulic Cylinder Leakage, Aalborg Universitet, Master Thesis 